\title{
Use of bottom-mounted echo sounders in exploring behavior of mesopelagic fishes
}

\author{
Stein Kaartvedt ${ }^{1,2, *}$, Anders Røstad ${ }^{1}$, Thor A. Klevjer ${ }^{1}$, Arved Staby ${ }^{2}$ \\ ${ }^{1}$ Department of Biology, University of Oslo, PO Box 1066 Blindern, 0316 Oslo, Norway \\ ${ }^{2}$ Deparment of Biology, University of Bergen, PO Box 7800, 5020 Bergen, Norway
}

\begin{abstract}
We deployed an upward-facing echo sounder mounted on the bottom and cabled to shore in a $\sim 400 \mathrm{~m}$ fjord location for long-term studies of small mesopelagic fish and their potential predators. The population of the myctophid Benthosema glaciale displayed diverse diel vertical migration (DVM) behaviors, including normal DVM to surface waters at night, reverse DVM in the lower part of the water column in which fish ascended to $\sim 200 \mathrm{~m}$ at day, as well as nonmigration of some individuals. The relative prevalence of these behavioral modes varied with season. Acoustic target tracking of individuals in deep water showed that B. glaciale was conspicuously inactive and drifted back and forth with weak tidal currents, essentially acting as plankton. Swimming was largely restricted to infrequent short bouts. More active swimming occasionally occurred in the vertical direction, and then in a stepwise pattern. Potential predators in deep water were swimming at speeds of $<0.5$ body length $\mathrm{s}^{-1}$, with maximum speeds of $\sim 1$ body length $\mathrm{s}^{-1}$. These results show that submerged echo sounders provide a means of non-intrusively studying both individual and population behavior of deep-living organisms.
\end{abstract}

KEY WORDS: Mesopelagic - Diel vertical migration - Swimming behavior - Target tracking · Benthosema glaciale $\cdot$ Moored echo sounders

\section{INTRODUCTION}

The most common application of echo sounders in marine biological research has been in stock assessments of fish, in which volume backscatter is converted into fish biomass (Dragesund \& Olsen 1965). It has also been documented that organisms constituting deep acoustic scattering layers carry out diel vertical migration (DVM) (Moore 1950, Hersey \& Backus 1954), and acoustic studies of such migrations have become a field of research (e.g. Boden \& Kampa 1967). Subsequent applications comprised assessments of plankton abundance and size distribution (e.g. Holliday \& Pieper 1980, Greene et al. 1989, Everson et al. 1990). Echo sounders are now increasingly used for behavioral studies of plankton (DeRobertis et al. 2000, Genin et al. 2005, Kaartvedt et al. 2007) and fish (Huse \& Ona 1996, Handegard \& Tjøstheim 2005, Mehner 2006) and for in situ studies of predator-prey relationships (e.g.
Zamon et al. 1996, Nøttestad et al. 2002, Kaartvedt et al. 2005).

Acoustic studies have normally been conducted from moving vessels, using hull-mounted transducers. As compact echo sounders that can be kept submerged in pressurized housings are now available, acoustics can be used in telling quite new stories. Stationary splitbeam echo sounders can reveal the movements of individuals traversing the acoustic beam both horizontally and vertically (Ehrenberg \& Torkelson 1996), and submerged echo sounders make it possible to establish the in situ swimming behavior of fish in deeper waters (Huse \& Ona 1996). Autonomous systems may be battery powered and left at sea (Thomson \& Allen 2000, Trevorrow 2005, Brierley et al. 2006), or they can be cabled to land for power and transmission of data (Patel 2007). Simple, moored and cabled systems enable detailed, long-term and relatively low-cost studies, in contrast to studies made from research vessels. 
Understanding ecosystem functioning and managing marine resources properly require knowledge of individual behavior, since activity levels and swimming behavior affect the distribution of organisms, the interactions between predators and prey (Gerritsen \& Strickler 1977, Wright \& O'Brien 1984, O'Brien et al. 1990) and bioenergetic budgets (Torres \& Childress 1983, Huse \& Ona 1996). The remote and inaccessible nature of mesopelagic and deep-sea habitats has largely precluded direct observations of their inhabitants. Here, we show that submerged, stationary echo sounders may provide detailed information on the behavior of small mesopelagic fish and their potential predators in their natural environment. We present data from a bottom-mounted, upward facing echosounder that was cabled to shore in a Norwegian fjord. This approach provides a stable platform; the procedure is non-intrusive and imposes virtually no limitation on operation time and data storage capacity.

\section{MATERIALS AND METHODS}

A mooring with an upward-facing, calibrated echo sounder (Simrad EK 60, $38 \mathrm{kHz}, 7.1^{\circ}$ beam width) was deployed at $390 \mathrm{~m}$ depth in Masfjorden, Norway. The transceiver was housed in a glass sphere (pressure proof to $3000 \mathrm{~m}$ ) next to an oil-filled transducer (Simrad ES38DD, $38 \mathrm{kHz}$; pressure proof to $1500 \mathrm{~m}$ ), which was mounted in a steel frame with gimbal couplings to ensure horizontal orientation of the transducer surface. The echo sounder was connected to land with $1200 \mathrm{~m}$ of cable that provided electricity and transmitted data to a PC on shore. We used an input voltage of $220 \mathrm{~V}$, but applied a $12 \mathrm{~V}$ transformer that was installed next to the transceiver within the glass sphere, as it appeared that this voltage gave less electrical noise in the acoustic records. Standard industrial modems were used to transmit data. The temporal resolution of data (ping rate) was $1 \mathrm{~s}^{-1}$, and the pulse length was $0.512 \mathrm{~ms}$. All raw data were stored for later analyses.

The mooring was deployed in July 2007 and was retrieved after 15 mo of measurements. Upon retrieval, the echo sounder was immediately redeployed at 300-400 m depth together with a standard copper sphere target to verify if the system was calibrated at the operation depth.

Here, we present results from three different periods (22-23 July, 29-30 August and 5-6 November 2007) to illustrate different types of information that were obtained using this approach. Results are given at 3 levels of resolution. Echograms display records from the entire water column for three $48 \mathrm{~h}$ periods, focusing on acoustic scattering layers, which verified that that display population behavior. Due to the large amount of data obtained, each pixel was based on the average of 15 pings when the echograms were visualized in Matlab. 'Echo traces' refer to records from single organisms (seen as a 'line') in a normal echogram. Acoustic 'tracks' are based on targets for which both horizontal and vertical position, as well as target strength (TS, a proxy for size) are known. In this case, the criteria for accepting echoes are stricter, so that some or all echoes that are seen in an echo trace may become rejected by the tracking algorithms. In all presentations, time is in UTC (coordinated universal time), which is one hour after standard local time.

Target tracking (TT) was used to assess the behavior of individual fish by grouping sequential echoes into tracks. In this procedure, subsequent echoes were merged to make up the swimming path and speed of an individual, or to assess the TS. Tracking can be performed automatically, using algorithms utilizing information on the proximity of sequential echoes in determining the tracks, or manually, with the researcher visually selecting which echoes to include in the tracks. Results from both types of procedures are presented here. The advantage of the automatic tracking algorithms is its objectivity, but the downsides are that longer trajectories typically get fragmented (Xie 2000), or trajectories of different organisms may become combined into a single track. In manual tracking, on the other hand, echo traces that evidently originate from single organisms are subjectively selected from the echogram. Raw data making up a trace are imported into tracking software and can then be used to estimate the swimming paths, speed and target strength of that particular individual (Balk \& Lindem 2002).

Swimming velocities of small mesopelagic fish were assessed by automatic tracking, using the cross-filter detector of the Sonar5-Pro post-processing system at standard settings (Balk \& Lindem 2002). Individuals with TS between -52 and $-62 \mathrm{~dB}$ were tracked within a range of 20 to $70 \mathrm{~m}$ from the transducer (320 to $370 \mathrm{~m}$ depth). At shorter range, the acoustic beam was too narrow to obtain many successive pings, and further away, the numbers of targets became too high to be properly resolved. This is because the volume of the cone-shaped acoustic beam increases with range, and resolution of individuals requires that only 1 acoustic target is present at a given range (pulse volume). If this condition is violated, multiple targets composed of echoes from >1 organism may cause corrupted records (Soule et al. 1997). A minimum of 25 echoes were required to make up a track, accepting a maximum of 5 missing pings. The majority of small mesopelagic fish were inactive most of the time; thus, echo traces that displayed vertical swimming were selected in additional manual tracking to assess vertical velocities.

Targets with TS of >-50 dB were tracked separately. The single target echoes were detected in Sonar5-Pro 
using respective minimum and maximum echo lengths of 0.8 and 1.2 , with a maximum phase deviation of 0.8 . A minimum of 10 echoes were required to make up a track, with maximally 1 ping missing. These less numerous, larger fishes could be studied at longer range. Two size classes appeared to be present at different distances from the bottom, and results are presented for the 20-90 and 90-190 m range respectively (i.e. 300-370 and 200-300 m depth). The shallowest mode performed DVM during summer and then came within reach for TT when the fish descended in daylight. These fish had the strongest TS, and since the risk of recording multiple (hence larger) targets increases with range, we visually scrutinized echo traces of individual fish to make sure that only 1 fish was included in each track.

Correct swimming speed depends on correct measurements of positions in the acoustic beam. Errors introduced by the system's angular resolution (Brede et al. 1990) and erroneous angle measurements (Mulligan \& Chen 2000) will add artificial movements to the targets and therefore overestimate swimming speeds. This bias will increase with range. Such errors can be reduced by smoothing. Handegard et al. (2005) and Røstad (2006) eliminated this range dependency (at a range of up to $125 \mathrm{~m}$ ) by using linear regression to smooth the estimated echo positions, and we used the same approach in this study. Also in our case, this smoothing appeared to be successful, as no clear effect of range was recorded for fish tracked between 90 and $190 \mathrm{~m}\left(\mathrm{R}^{2}{ }_{\mathrm{Jul}}=0.01 ; \mathrm{R}^{2}\right.$ Aug $=$ $\left.0.07, R^{2}{ }_{\text {Nov }}=0.11\right)$. In July, there was an effect of range on swimming speed within the deepest interval $\left(\mathrm{R}^{2}{ }_{20-90 \mathrm{~m}}=\right.$ 0.29 ), which we ascribe to inclusion of some larger faster swimming targets at long range.

Acoustic studies are normally accompanied by sampling to identify and obtain biological information on acoustic targets. Because of its nature, continuous long-term acoustic records cannot be accompanied by an equivalent sampling resolution. Masfjorden was selected as the study site since its mesopelagic fish fauna is well established from previous sampling. Investigations over many years and from different seasons have shown a consistent presence of the lightfish Maurolicus muelleri that form conspicuous acoustic scattering layers in mid-waters, and the northern lanternfish Benthosema glaciale in lower layers (Kaartvedt et al. 1988, Giske et al. 1990, Baliño \& Aksnes 1993, Bagøien et al. 2001). For this study, we carried out a sampling campaign with repeated trawling in the acoustic layers on 1 to 4 November 2007, i.e. with acoustics and sampling overlapping in time for one of the periods presented here (although we present acoustic data for the 2 days subsequent to the sampling campaign, since the ship's echo sounders interfered with records from the mooring). We used a Harstad trawl equipped with a multisampler cod end that can be remotely opened and closed during sampling (Engås et al. 1997), hence providing depth stratified catches. In total, 29 trawl samples were obtained from different parts of the water column during day and night.

\section{RESULTS}

\section{Scattering layers and trawl catches}

The echograms were dominated by a strong scattering layer, with daytime depths near 150 to $200 \mathrm{~m}$, and carrying out DVM in July and August, but barely doing so in November (Fig. 1). Catches (Table 1) and previous studies identify this scattering layer as consisting of the lightfish Maurolicus muelleri, with juveniles of this species likely forming the weaker layer

Table 1. Trawl catches. Average catch (no. $\left.\mathrm{h}^{-1} ; \#\right)$, average contribution to total catch in weight $(\%)$ and average lengths $(\mathrm{L} ; \mathrm{mm})$ of the major taxa in day and night tows summarised by depth ranges (Masfjorden, November 2007). SDs of mean lengths are indicated in parentheses

\begin{tabular}{|c|c|c|c|c|c|c|c|c|c|c|c|c|c|c|c|c|c|c|c|}
\hline & & \multicolumn{3}{|c|}{$<50$} & \multicolumn{3}{|c|}{$50-100$} & \multicolumn{3}{|c|}{$100-150$} & \multicolumn{3}{|c|}{$150-200$} & \multicolumn{3}{|c|}{$250-300$} & \multicolumn{3}{|c|}{$>300$} \\
\hline & & $\#$ & $\%$ & $\mathrm{~L}$ & \# & $\%$ & L & $\#$ & $\%$ & L & $\#$ & $\%$ & L & $\#$ & $\%$ & L & \# & $\%$ & $\mathrm{~L}$ \\
\hline \multirow{2}{*}{$\begin{array}{l}\text { Maurolicus } \\
\text { muelleri }\end{array}$} & Day & & & & 3694 & 98.2 & $24(3)$ & \multirow[t]{2}{*}{39938} & \multirow[t]{2}{*}{99.8} & $40(4)$ & & & & 112 & 4.2 & $41(6)$ & 72 & 2.9 & $40(4)$ \\
\hline & Night & 665 & 23.4 & $31(8)$ & 93 & 5.8 & $38(5)$ & & & & 1159 & 61.1 & $38(4)$ & 49 & 1.2 & $41(5)$ & 0 & 0 & \\
\hline \multirow{2}{*}{$\begin{array}{l}\text { Benthosema } \\
\text { glaciale }\end{array}$} & Day & & & & 0 & 0 & & \multirow[t]{2}{*}{0} & \multirow{2}{*}{\multicolumn{2}{|c|}{0}} & & & & 494 & 71.7 & $59(5)$ & 536 & 65.7 & $59(5)$ \\
\hline & Night & 62 & 18.0 & $55(8)$ & 29 & 4.8 & $53(6)$ & & & & 85 & 9.1 & $54(8)$ & 1252 & 84.6 & $60(5)$ & 237 & 82.2 & $60(5)$ \\
\hline \multirow{2}{*}{$\begin{array}{l}\text { Pelagic } \\
\text { shrimps }\end{array}$} & Day & & & & 2 & 1.7 & & \multirow[t]{2}{*}{0} & \multirow{2}{*}{\multicolumn{2}{|c|}{0}} & & & & 374 & 23.9 & $74(8)$ & 388 & 31.4 & $66(8)$ \\
\hline & Night & 257 & 42.2 & $65(15)$ & 507 & 89.2 & $71(7)$ & & & & 244 & 28.8 & 75 (11) & 413 & 14 & $62(7)$ & 97 & 17.1 & $68(5)$ \\
\hline \multirow[t]{2}{*}{ Krill } & Day & & & & 2 & 0 & 19 & \multirow[t]{2}{*}{195} & \multirow[t]{2}{*}{0.20} & $38(3)$ & & & & 8 & 0.1 & $41(3)$ & 0 & 0 & \\
\hline & Night & 562 & 16.2 & $40(4)$ & 3 & 0.20 & $39(4)$ & & & & 41 & 0.9 & $40(4)$ & 35 & 0.2 & $41(2)$ & 17 & 0.7 & $38(4)$ \\
\hline \multirow{2}{*}{$\begin{array}{l}\text { Number of } \\
\text { tows }\end{array}$} & Day & & & & & 3 & & \multirow{2}{*}{\multicolumn{3}{|c|}{3}} & \multirow{2}{*}{\multicolumn{3}{|c|}{3}} & \multicolumn{3}{|c|}{3} & \multicolumn{3}{|c|}{3} \\
\hline & Night & & 7 & & & 3 & & & & & & & & \multicolumn{3}{|c|}{3} & \multicolumn{3}{|c|}{1} \\
\hline
\end{tabular}



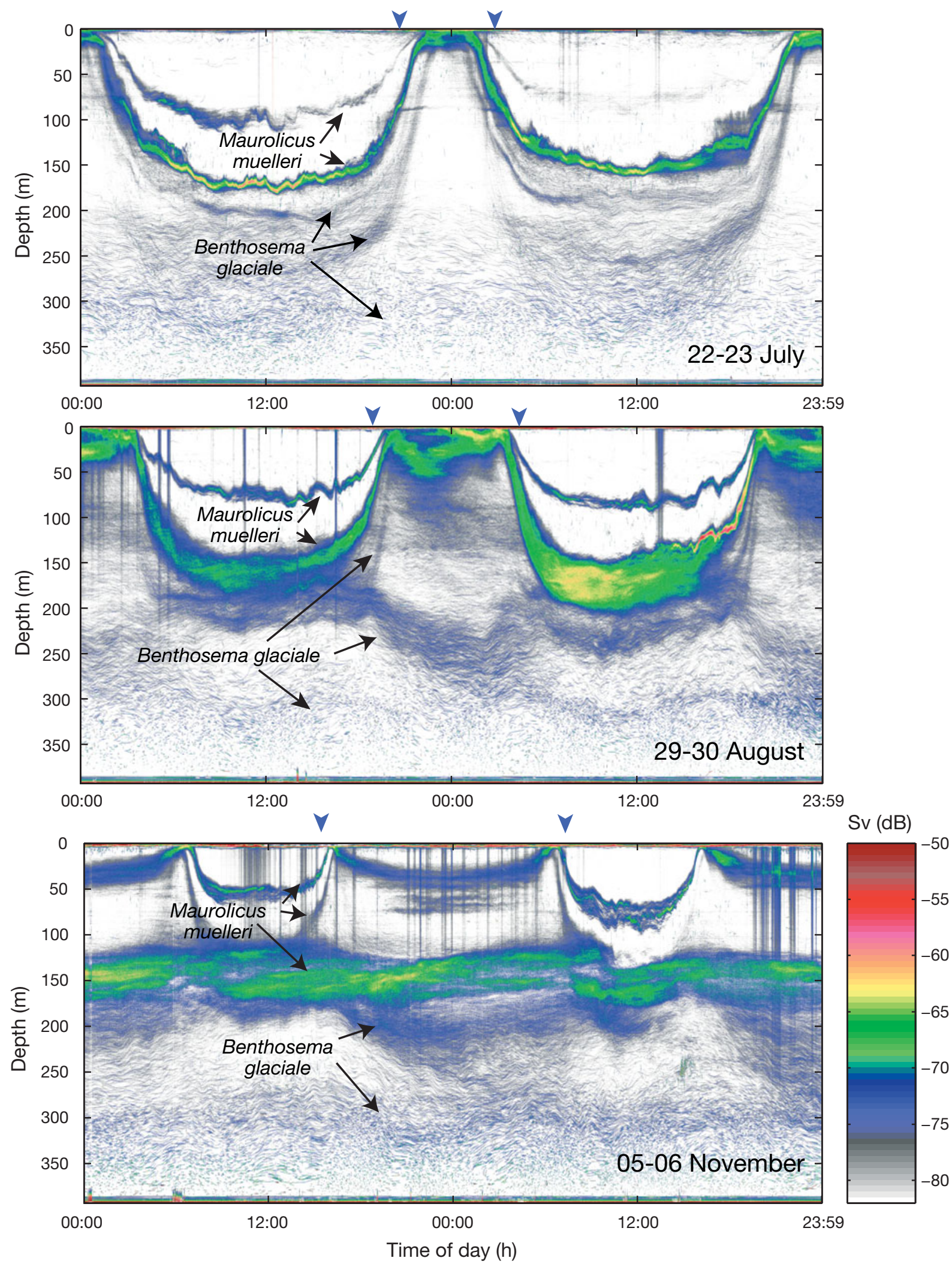

Fig. 1. Echograms for 22-23 July, 29-30 August and 5-6 November 2007. Color scale refers to backscattering strength (Sv) values $(\mathrm{dB})$. Species of the fish making up scattering layers are indicated; additional vertical 'lines' (most prominent in November) are generated by rain. Blue arrowheads: times of sunset and sunrise 
above. Here, we focus on the echoes below $\sim 200 \mathrm{~m}$, which we mainly ascribe to the lanternfish Benthosema glaciale based on the catches and previous studies. In November 2007, B. glaciale (average standard length of $6 \mathrm{~cm}$ ) prevailed in catches below $250 \mathrm{~m}$ (Table 1), being numerically dominant in 8 of 9 samples taken. Also, pelagic shrimps (primarily Sergestes arcticus) were common in the deep catches. No $B$. glaciale were captured above $150 \mathrm{~m}$ during the day, while some individuals were captured in the upper 50 $\mathrm{m}$ at night (Table 1).

In July, Benthosema glaciale undertook normal DVM (Fig. 1). However, part of the population ( 30\% of total acoustic backscatter) remained at depth. In August, the DVM patterns of B. glaciale changed. The upper part of the registrations allocated to this species continued to undertake normal DVM, but fish deeper in the water column now rather reversed their DVM (Fig. 1), with a component of the population ascending to $\sim 200 \mathrm{~m}$ in the morning and descending in the evening. A third component of the population remained at depth ( $40 \%$ of total backscatter). The daytime ascent persisted in November, with normal DVM of B. glaciale becoming inconspicuous in the acoustic records (Fig. 1). Approximately $50 \%$ of the population (in terms of acoustic backscatter) did not take part in the reverse migrations in November.

\section{Individual behavior}

\section{Benthosema glaciale}

Echo traces of individual Benthosema glaciale depicted slow internal waves with maximum vertical speeds of $\sim 2 \mathrm{~mm} \mathrm{~s}^{-1}$ (Fig. 1, although this is not easily seen in these compressed plots). Long echo traces showed that $B$. glaciale remained within the stationary acoustic beam for prolonged periods, with many consecutive acoustic returns from the same individual. TT documented that this could be ascribed to low activity, and revealed that $B$. glaciale were drifting back and forth with weak tidal currents (Fig. 2). Currents were strongest in August and November, resulting in a $\sim 6 \mathrm{~h}$ cyclic pattern in the population's net horizontal movements with peak velocities of $\sim 3 \mathrm{~cm} \mathrm{~s}^{-1}$ and the direction being reversed between peaks (Fig. 2). Low population velocities (i.e. currents) were recorded in July (maxima of $\sim 1.5 \mathrm{~cm} \mathrm{~s}^{-1}$ ). Subtracting hourly population averages of the physical displacement from the individual tracks resulted in very slow individual movements (Fig. 3), with medians of 1.1 (median $\mathrm{TS}=$ $-57.8 \mathrm{~dB}$ ), 1.2 (median TS $=-58.7 \mathrm{~dB}$ ) and $0.8 \mathrm{~cm} \mathrm{~s}^{-1}$ (median TS $=-58.4 \mathrm{~dB}$ ) in July, August and November, respectively. Essentially, these fish were functionally

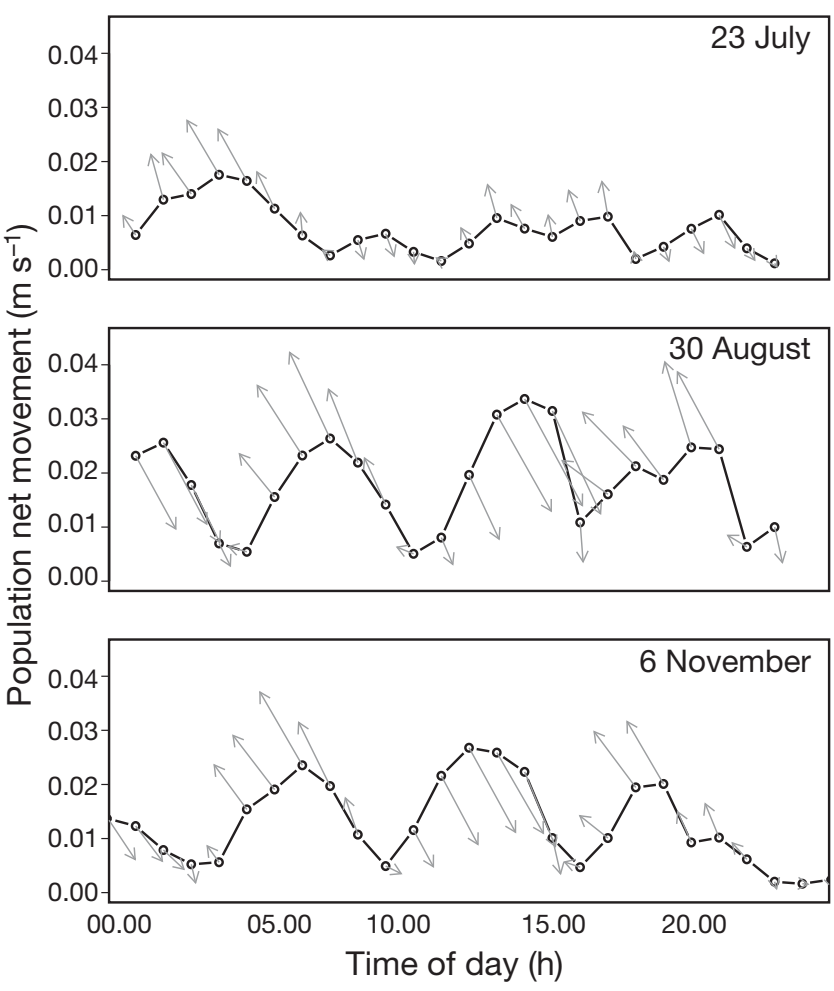

Fig. 2. Net horizontal population displacement of targets ascribed to Benthosema glaciale on 23 July $\left(\mathrm{n}_{\text {track }}=7636\right.$; median TS $=-57.8 \mathrm{~dB}), 30$ August $2007\left(\mathrm{n}_{\text {track }}=8012\right.$; median $\mathrm{TS}=-58.7 \mathrm{~dB})$ and 6 November $\left(\mathrm{n}_{\text {track }}=11520 ;\right.$ median $\mathrm{TS}=$ $-58.4 \mathrm{~dB}$ ). Arrows depict relative direction and relative speed of displacement. The results are based on automatic tracking. Numbers of fish will be lower than numbers of tracks since automatic tracking tends to split long tracks into several shorter ones

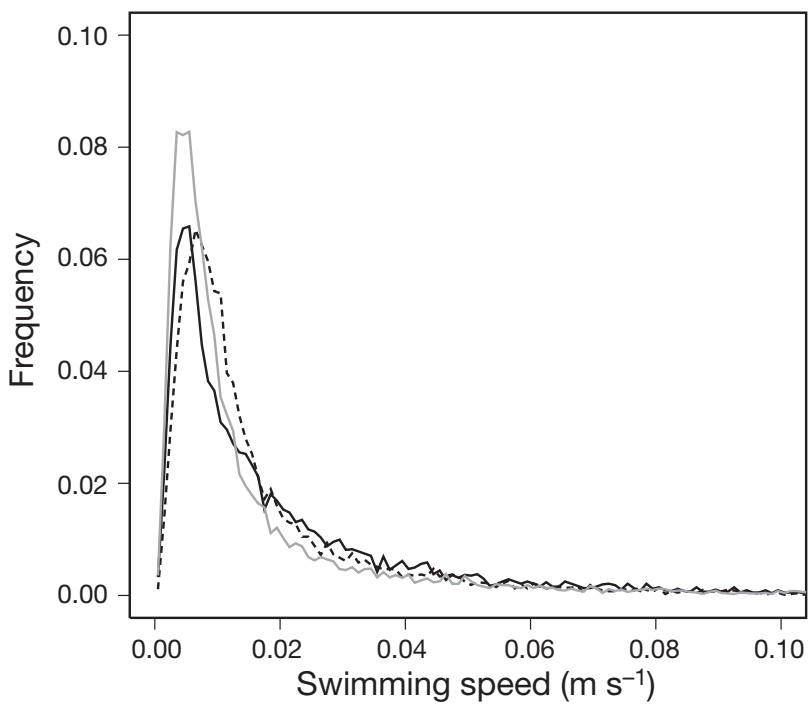

Fig. 3. Individual swimming speed (population net movement subtracted) of targets ascribed to Benthosema glaciale. (-) 23 July, (- 30 August, (---) 6 November 2007 

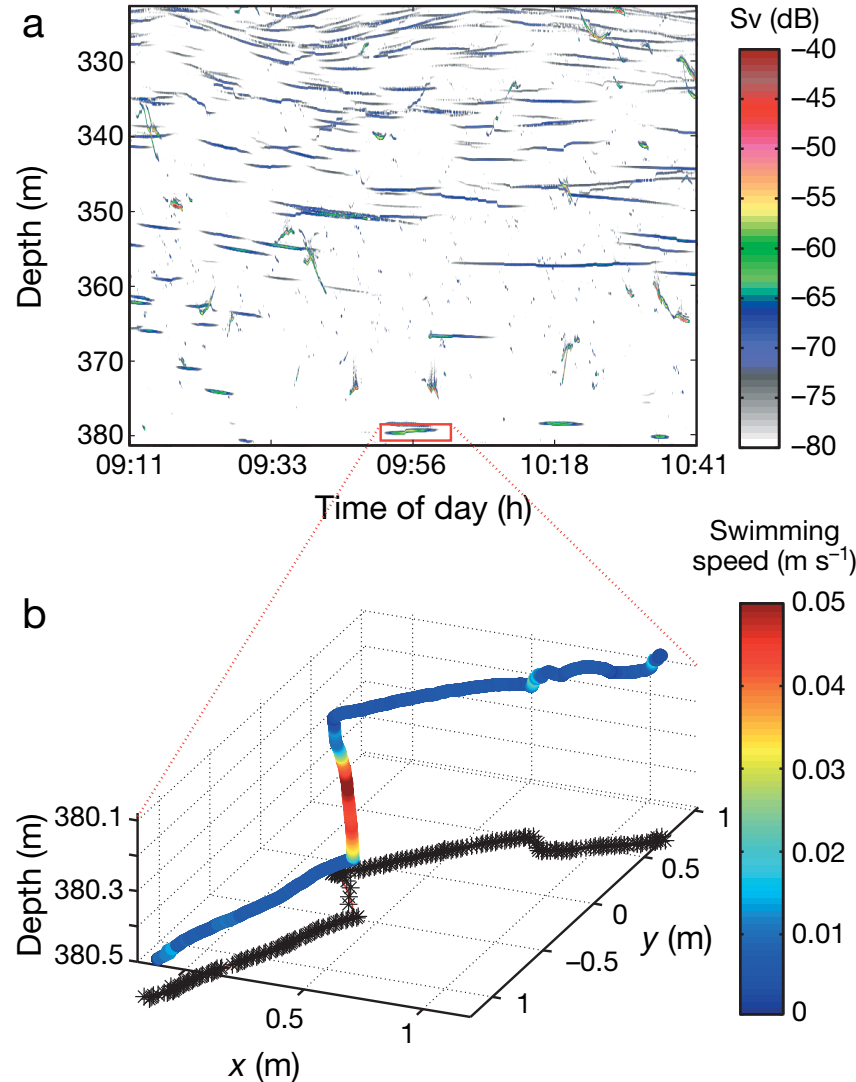

Fig. 4. (a) Echo traces of Benthosema glaciale (mostly blue or greenish) and larger fish (red, shorter-lasting traces). Color scale refers to $\mathrm{Sv}$ values (dB). (b) Example of 3-D relocation and swimming speed of a target ascribed to $B$. glaciale (framed in (a)) at $380 \mathrm{~m}$ depth on 30 August. Color scale refers to swimming speed $\left(\mathrm{m} \mathrm{s}^{-1}\right)$

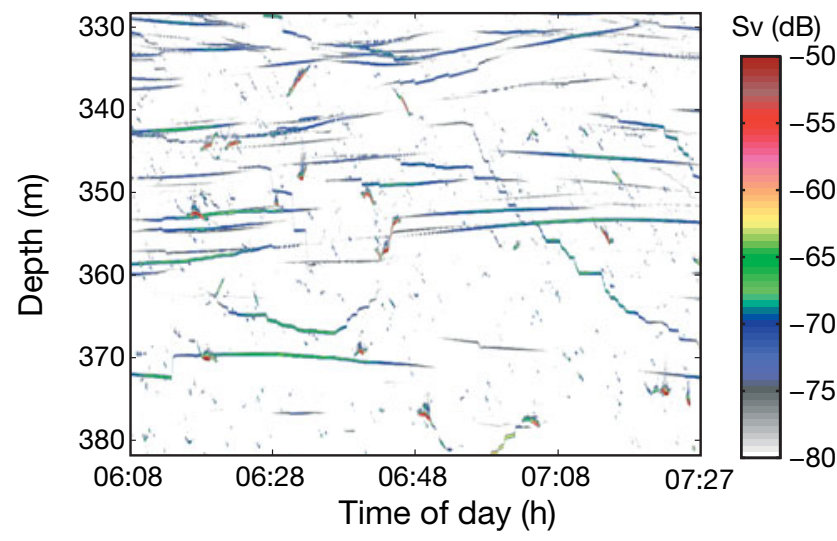

Fig. 5. Echo traces of individual fish on 23 July, showing both inactive fish and individuals swimming vertically in a stepwise fashion. The figure depicts echo traces both of Benthosema glaciale (mostly blue or greenish echo traces) and larger fish (red, shorter-lasting traces) behaving like plankton even in very weak currents. Nevertheless, drifting individuals displayed infrequent small shifts in vertical position that were associated with short, horizontal swimming bouts (e.g. Fig. 4), before the fish came to rest again.

Some individuals exhibited more active swimming in the vertical direction, and their echo traces displayed a staircase-like stop-and-go pattern (e.g. Fig. 5). Fish that relocated in the vertical plane in one or more steps were selectively picked for assessing vertical swimming speeds and direction, using manual tracking during the vertical relocation. Benthosema glaciale generally shifted position at $\sim 3-5 \mathrm{~cm} \mathrm{~s}^{-1}$, both when ascending and descending, with maximum velocities of $\sim 8 \mathrm{~cm} \mathrm{~s}^{-1}$ (Fig. 6). Individuals were swimming both upwards and downwards during both day and night. The TS appeared to be slightly lower during vertical relocation ( 1-2 dB when ascending) than when drifting horizontally.

\section{Potential predators}

The acoustic analyses suggested 2 groups of larger fish (potential predators) in the lower parts of the water

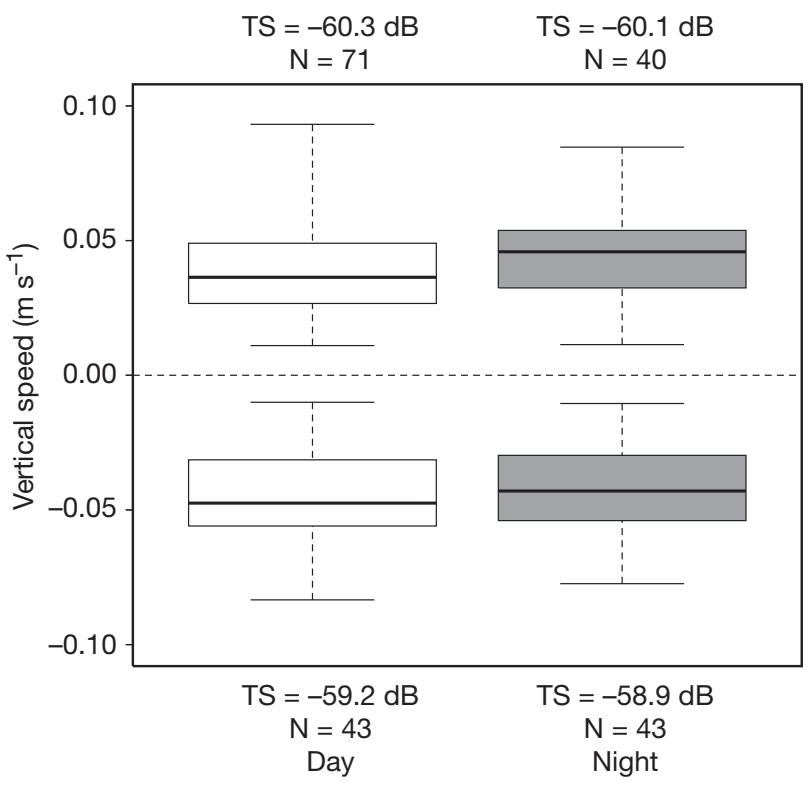

Fig. 6. Vertical speeds during relocation day (left) and night (right) of targets ascribed to Benthosema glaciale. The results are based on manual tracking of ascending (upper panel) and descending (lower panel) individuals, respectively (combined for July, August and November). The boxes encompass the 25th to 75th percentiles; whiskers denote maximum and minimum values, and the horizontal lines inside the boxes denote median swimming speeds. Median target strength (TS) and numbers of tracks are given 

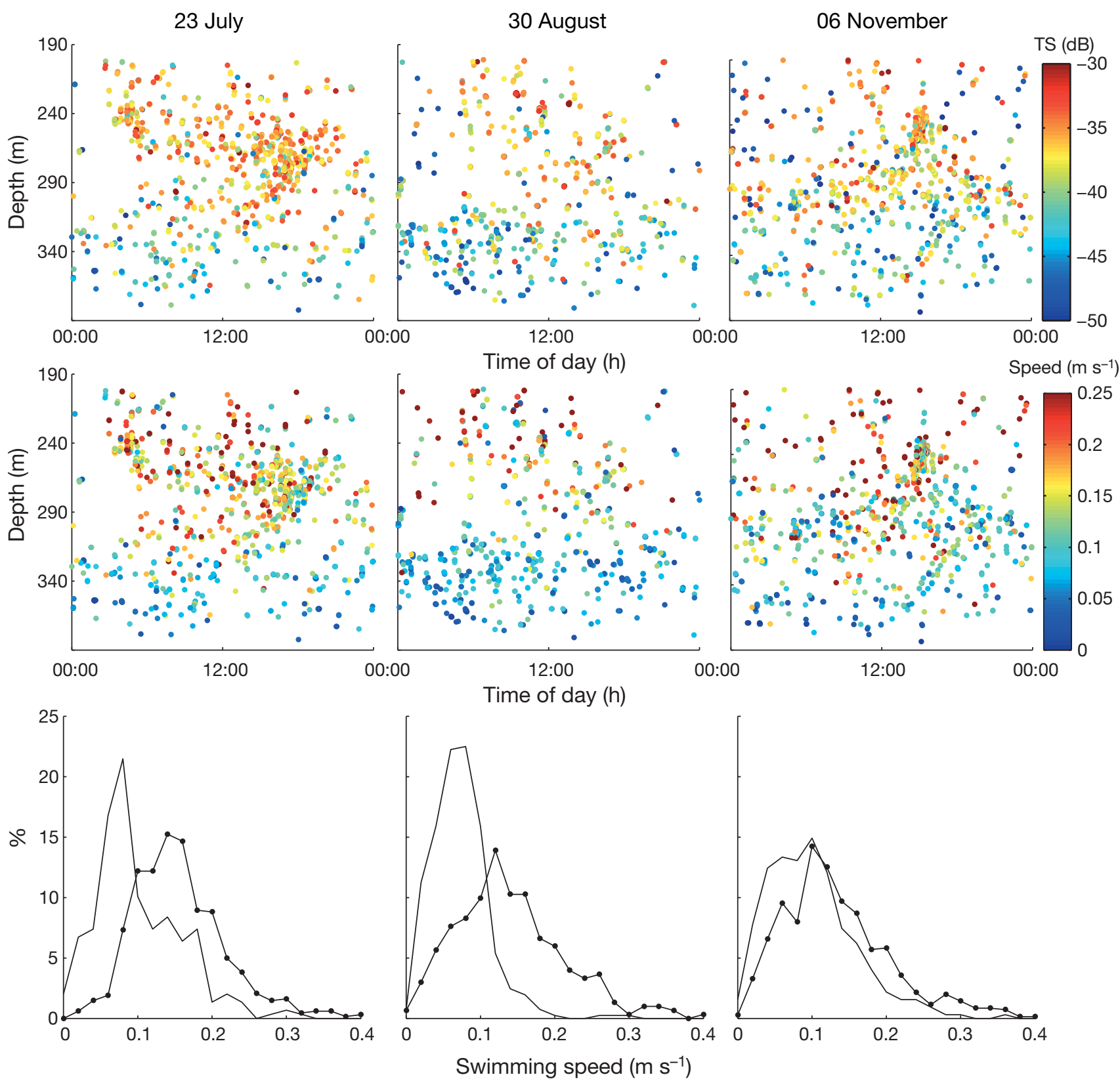

Fig. 7. Results from target tracking of fish with target strength (TS) >-50 dB for 23 July (left), 30 August (middle) and 6 November (right). Each dot represents an individual fish. Color scales in upper and middle panels are TS (dB) and swimming speed (m s ${ }^{-1}$ ), respectively. Lower panel shows the distribution of swimming speeds for fish between $200-300 \mathrm{~m}\left(\rightarrow-: \mathrm{n}_{\text {trackJul }}=681 ; \mathrm{n}_{\text {trackAug }}=301\right.$; $\left.\mathrm{n}_{\text {trackNov }}=685\right)$ and below $300 \mathrm{~m}\left(-: \mathrm{n}_{\text {trackJul }}=290 ; \mathrm{n}_{\text {trackAug }}=401 ; \mathrm{n}_{\text {trackNov }}=306\right)$

column (Fig. 7). There appeared to be a size shift at $\sim 300 \mathrm{~m}$ depth (90 $\mathrm{m}$ above bottom), and fish above and below this depth are treated separately in the analyses. The near-bottom component (median TS $=-39.9 \mathrm{~dB}$, -41.4 and $-41.0 \mathrm{~dB}$ in July, August and November, respectively) was present during day and night. They were cruising at moderate speed (Fig. 7), with respective medians of 8,7 and $9 \mathrm{~cm} \mathrm{~s}^{-1}$ in July, August and November, and maximum velocities of $\sim 25 \mathrm{~cm} \mathrm{~s}^{-1}$. Sev- eral such fishes can be seen in Figs. 4 \& 5, as characterized by stronger (red in color) and shorter echo traces (due to their higher swimming speed) than that of Benthosema glaciale.

The fish above $300 \mathrm{~m}$ (median TS $=-36.0,36.5$ and $-36.9 \mathrm{~dB}$ ) were swimming with median speeds of 15 , 13 and $12 \mathrm{~cm} \mathrm{~s}^{-1}$ for July, August and November respectively, with maximum velocities approaching 30 to $40 \mathrm{~cm} \mathrm{~s}^{-1}$ (Fig. 7). 


\section{DISCUSSION}

Moored echo sounders facilitate non-intrusive, longterm studies of both individual and population behavior of deep-living organisms. Results for the 3 timewindows presented here exemplify types of findings obtainable using this approach. These examples provide new information on DVM behavior of mesopelagic fish and details on their individual swimming.

We are confident that the identity of the acoustic targets is correctly established. Results from sampling in this study concur with those from repetitive sampling over the years (see Material \& Methods), and for all samples below $250 \mathrm{~m}$ combined, with Benthosema glaciale constituting $58 \%$ of the catches in terms of numbers. The other common group in the deep catches (pelagic shrimps, $32 \%$ of numbers in total) would make considerably weaker echoes (Benoit-Bird \& Au $2001,2006)$. The scattering layer focused on here is also recorded at $18 \mathrm{kHz}$ (Kaartvedt et al. 2008), and scattering from mesopelagic fishes would be the predominant cause of acoustic reverberation at this frequency (Love et al. 2004).

The population of Benthosema glaciale displayed diverse DVM behavior, and comprised individuals carrying out normal DVM with ascent at night, individuals carrying out reverse DVM with ascent at day, as well as nonmigrating individuals. To our knowledge, documentation of reverse DVM is a novel finding for $B$. glaciale and for mesopelagic fish in general. We suggest that the reverse migrations at mesopelagic depths can be explained by visual foraging on mid-water plankton during the day, with a subsequent descent as feeding terminates in the deep, dark waters at night. Mesopelagic fish with dark-adapted eyes may be able to see their plankton prey at several hundred meters depth in daylight (Warrant \& Locket 2004). Potential prey in mid-water comprises seasonally migrating copepods (Calanus spp.) which tend to be centered at 150-250 $\mathrm{m}$ depth in this fjord during autumn (Bagøien et al. 2001), and which would be most easily spotted visually in the upper part of this range. Moreover, organisms carrying out normal DVM, like krill, may be spotted visually in mid-waters during daytime. Such hypotheses derived from the acoustic observations can be tested by sampling.

Normal DVM prevailed in July. Nocturnal ascent is normally ascribed to feeding on surface plankton at night (Roe \& Badcock 1984, Pearre 2003), and plankton flourishes in upper layers during summer. Normal and reverse DVM of Benthosema glaciale co-occurred at the end of August. Only reverse migration was recorded acoustically for this species in November (when surface mesozooplankton populations are expectedly dilute), yet trawl catches documented some normal DVM.
There were always records of nonmigrating fish in the lower part of the water column. Since we could observe individual fish over long periods, we can conclude that the presence of fish in deep water throughout the diel cycle was not a result of asynchronous migrations (cf. Pearre 2003). Moreover, previous studies have concluded that populations of mesopelagic fish may separate into migrating and nonmigrating groups. Sutton \& Hopkins $(1996 a, b)$ suggested that migrating individuals were feeding in upper layers at night, while individuals remaining at depth were in a digesting, or in a post-digestion state. Pearcy et al. (1979) suggested that a population of lanternfish split into nonmigrating individuals feeding at depth, and migrating individuals feeding in upper layers at night.

Individual fish likely adjust their migration pattern according to both external stimuli and internal state. It is well established that different parts of a population can behave differently due to factors like age (Giske \& Aksnes 1992), stored resources (Hays et al. 2001), hunger (Pearre 2003) or parasites (Barber et al. 2000), or because the population may consist of both risk seeking and risk averse individuals (Wolf et al. 2007). More long-term acoustic observations will evidently document more variation in fish behavior than currently established, thus improving our understanding of behavioral flexibility and ecosystem functioning.

Benthosema glaciale displayed little swimming activity, passively of drifting back and forth with tidal currents. Such lethargic behavior concurs with observations from remotely operated vehicles (ROVs) and submersibles that show midwater fish hanging motionless in the water column (Barham 1966, 1970, Backus et al. 1968), but deviates from observations of myctophids undertaking extensive nocturnal horizontal migrations onto and off Hawaiian Islands shelf regions (Benoit-Bird \& $\mathrm{Au}$ 2006, McManus et al. 2008). If $B$. glaciale were foraging during their tranquil state, the long duration of their trajectories, together with the intermittent, small shifts in their position, would suggest ambush feeding (cf. O'Brien et al. 1990). Kaartvedt et al. (2008) reported stepwise migration patterns for mesopelagic fish during DVM, as also shown for individual deep-living $B$. glaciale in this study. Such stop-and-go swimming concurs with saltatory search, in which fish scan the water for prey during the stationary phases, relocate and then scan a new volume (O'Brien et al. 1990).

Potential predatory fish were present in deep waters during both day and night. They were not allocated to species, but TSs of -40 and $-36 \mathrm{~dB}$ correspond to sizes of 23 and $37 \mathrm{~cm}$ respectively, applying a standard conversion factor for gadoids (Foote 1987). For both groups, the median swimming speed would correspond to $\sim 1 / 3$ body length $\mathrm{s}^{-1}$, as derived from the acoustic determination of size. Visual range is low in 
the dark, deep waters, and if these fishes were indeed predators on the lethargic Benthosema glaciale, slow swimming might be a way of minimizing hydrodynamic noise. Potential prey will be less able to note the approach of a 'silent' predator. Hydrodynamic silence would also facilitate prey detection for tactile predators in dark waters (Janssen et al. 1999).

\section{PERSPECTIVES}

In order to understand ecosystem functioning, it is necessary to unveil processes and interactions involving individual organisms (Kerfoot \& Sih 1987, Williamson 1993). We have presented some examples of the usefulness of submerged, stationary echo sounders for providing information at the individual as well as the population level. This approach enables studies of even $\mathrm{cm}$-sized organisms and their potential predators in their undisturbed natural environment at depths of several hundred meters and at time scales of seconds to years. Fjords are deep, their faunal composition resembles that of the adjacent ocean, and low advection provides good opportunities for target tracking. Such systems can be used as low-cost ocean laboratories to obtain high-resolution data for e.g. testing and parameterizing mechanistic predator-prey models.

Moored echo sounders have also proven their abilities in other environments, including freshwater (Cech \& Kubecka 2002, Mehner 2006), coastal bays (Axenrot et al. 2004), coral reefs (Genin et al. 2005) and shelf ecosystems (e.g. Benoit-Bird \& Au 2006), and acoustic moorings are becoming increasingly used for studies of the pelagic fauna even in remote and inaccessible environments (Brierley et al. 2006, Cottier et al. 2006). We are now on the verge of establishing large-scale cabled ocean observatories that are equipped with an array of environmental sensors on the bottom of the world oceans (e.g. Malakoff 2004). Echo sounders have the potential of contributing considerably to these endeavors to understand the physics of the oceans, their organisms and ecosystem functioning. Implementation of new and innovative infrastructure requires qualified researchers who know the possibilities and limitations of new techniques, and who can pose the right questions and handle the vast data streams. In parallel with the focus on logistics of new technologies like ocean observatories, there is a need to build competence among aquatic ecologists to exploit acoustic methods to their full benefit.

\section{LITERATURE CITED}

> Axenrot T, Didrikas T, Danielsson C, Hansson S (2004) Diel patterns in pelagic fish behaviour and distribution observed from a stationary, bottom-mounted, and upwardfacing transducer. ICES J Mar Sci 61:1100-1104
Backus RH, Craddock JE, Haedrich RL, Shores DL and others (1968) Ceratoscopelus maderensis: peculiar sound-scattering layer identified with this myctophid fish. Science 160:991-993

Bagøien E, Kaartvedt S, Aksnes DL, Eiane K (2001) Vertical distribution and mortality of overwintering Calanus. Limnol Oceanogr 46:1494-1510

Baliño BM, Aksnes DL (1993) Winter distribution and migration of the sound scattering layers, zooplankton and micronekton in Masfjorden, western Norway. Mar Ecol Prog Ser 102:35-50

Balk H, Lindem T (2002) Sonar4 and Sonar5-Pro post-processing systems. Operator manual. Lindem Data Acquisition

Barber I, Hoare D, Krause J (2000) Effects of parasites on fish behaviour: a review and evolutionary perspective. Rev Fish Biol Fish 10:131-165

Barham EG (1966) Deep scattering layer migration and composition: observations from a diving saucer. Science 151: 1399-1403

Barham EG (1970) Deep-sea fishes lethargy and vertical orientation. In: Farquhar GB (ed) Proceedings of an international symposium on biological sound scattering in the ocean. Ocean Science Program, Washington, DC, p 100-118

Benoit-Bird KJ, Au WWL (2001) Target strength measurements of Hawaiian mesopelagic boundary community animals. J Acoust Soc Am 110:812-819

Benoit-Bird KJ, Au WWL (2006) Extreme diel horizontal migrations by a tropical nearshore resident micronekton community. Mar Ecol Prog Ser 319:1-14

Boden BP, Kampa EM (1967) The influence of natural light on the vertical migrations of an animal community in the sea. Symp Zool Soc Lond 19:15-26

Brede R, Kristensen FH, Solli H, Ona E (1990) Target tracking with a split-beam echo sounder. Rapp P-V Reùn Cons Int Explor Mer 189:254-263

Brierley AS, Saunders RA, Bone DG, Murphy EJ, Enderlein P, Conti SG, Demer DA (2006) Use of moored acoustic instruments to measure short-term variability in abundance of Antarctic krill. Limnol Oceanogr Methods 4:18-29

> Cech M, Kubecka J (2002) Sinusoidal cycling swimming pattern of reservoir fishes. J Fish Biol 61:456-471

Cottier FR, Tarling GA, Wold A, Falk-Petersen S (2006) Unsynchronised and synchronised vertical migration of zooplankton in a high Arctic fjord. Limnol Oceanogr 51: 2586-2599

DeRobertis A, Jaffe JS, Ohman MD (2000) Size-dependent visual predation risk and the timing of vertical migration in zooplankton. Limnol Oceanogr 45:1838-1844

Dragesund O, Olsen S (1965) On the possibility of estimating year-class strength by measuring echo-abundance of 0-group fish. Fiskeridir Skr Ser Havunders 13:47-75

Ehrenberg JE, Torkelson TC (1996) Application of dual-beam and split-beam target tracking in fisheries acoustics. ICES J Mar Sci 53:329-334

Engås A, Skeide R, West CW (1997) The 'multisampler': a system for remotely opening and closing multiple codends on a sampling trawl. Fish Res 29:295-298

Everson I, Watkins JL, Bone DG, Foote KG (1990) Implications of a new acoustic target strength for abundance estimates of Antarctic krill. Nature 345:338-340

> Foote KG (1987) Fish target strengths for use in echo integrator surveys. J Acoust Soc Am 82:981-987

Genin A, Jaffe JS, Reef R, Richter C, Franks PJS (2005) Swimming against the flow: a mechanism of zooplankton aggregation. Science 308:860-862

Gerritsen J, Strickler JR (1977) Encounter probabilities and 
community structure in zooplankton: a mathematical model. J Fish Res Board Can 34:73-82

Giske J, Aksnes DL, Ballno BM, Kaartvedt S and others (1990) Vertical distribution and trophic interactions of zooplankton and fish in Masfjorden, Norway. Sarsia 75:65-81

Giske J, Aksnes DL (1992) Ontogeny, season and trade-offs: vertical distribution of the mesopelagic fish Maurolicus muelleri. Sarsia 77:253-261

Greene CH, Wiebe PH, Burczynski J (1989) Analyzing zooplankton size distribution using high-frequency sound. Limnol Oceanogr 34:129-139

- Handegard NO, Tjøstheim D (2005) When fish meet a trawling vessel: examining the behaviour of gadoids using a free-floating buoy and acoustic split-beam tracking. Can J Fish Aquat Sci 62:2409-2422

- Handegard NO, Hjellvik V, Patel R (2005) Tracking individual fish from a moving platform using a split-beam transducer. J Acoust Soc Am 118:2210-2223

Hays GC, Kennedy H, Frost BW (2001) Individual variation in diel vertical migration of a marine copepod: why some individuals remain at depth when others migrate. Limnol Oceanogr 46:2050-2054

Hersey JB, Backus RH (1954) New evidence that migrating gas bubbles, probably the swim-bladders of fish, are largely responsible for scattering layers on the continental rise south of New England. Deep-Sea Res 1:190-191

Holliday DV, Pieper RE (1980) Volume scattering strengths and zooplankton distributions at acoustic frequencies between 0.5 and $3 \mathrm{MHz}$. J Acoust Soc Am 67:135-146

- Huse I, Ona E (1996) Tilt angle distribution and swimming speed of overwintering Norwegian spring spawning herring. ICES J Mar Sci 53:863-867

Janssen J, Sideleva V, Biga H (1999) Use of the lateral line for feeding in two Lake Baikal sculpins. J Fish Biol 54: 404-416

Kaartvedt S, Aksnes DL, Aadnesen A (1988) Winter distribution of macroplankton and micronekton in Masfjorden, western Norway. Mar Ecol Prog Ser 45:45-55

Kaartvedt S, Røstad A, Fiksen Ø, Melle W, Torgersen T, Breien MT, Klevjer T (2005) Piscivorous fish patrol krill swarms. Mar Ecol Prog Ser 299:1-5

Kaartvedt S, Klevjer TA, Torgersen T, Sørnes TA, Røstad A (2007) Diel vertical migration of individual jellyfish (Periphylla periphylla). Limnol Oceanogr 52:975-983

Kaartvedt S, Torgersen T, Klevjer TA, Røstad A, Devine JA (2008) Behavior of individual mesopelagic fish in acoustic scattering layers of Norwegian fjords. Mar Ecol Prog Ser 360:201-209

Kerfoot WC, Sih A (eds) (1987) Predation: direct and indirect impacts on aquatic communities. University Press of New England, Hanover, NH

Love RH, Fisher RA, Wilson MA, Nero RW (2004) Unusual swimbladder behavior of fish in the Cariaco Trench. Deep-Sea Res I 51:1-16

Malakoff D (2004) John Delaney profile. Marine geologist hopes to hear the heartbeat of the planet. Science 303: 751-752

McManus MA, Benoit-Bird KJ, Woodson CB (2008) Behavior exceeds physical forcing in the diel horizontal migration of the midwater sound-scattering layer in Hawaiian waters. Mar Ecol Prog Ser 365:91-101

> Mehner T (2006) Individual variability of diel vertical migrations in European vendace (Coregonus albula) explored by stationary vertical hydroacoustics. Ecol Freshwat Fish 15:146-153

> Moore HB (1950) The relation between the scattering layer and the Euphausiaceae. Biol Bull 99:181-212
Mulligan TJ, Chen DG (2000) Comment on 'Can stationary bottom split-beam hydroacoustics be used to measure fish swimming speed in situ?' by Arrhenius et al. Fish Res 49: 93-96

> Nøttestad L, Fernö A, Mackinson S, Pitcher T, Misund OA (2002) How whales influence herring school dynamics in a cold-front area of the Norwegian Sea. ICES J Mar Sci 59: 393-400

O'Brien WJ, Browman HI, Evans BI (1990) Search strategies of foraging animals. Am Sci 78:152-160

Patel R (2007) Surveillance of marine resources by use of stationary platforms and autonomous underwater vehicle (AUV). PhD thesis, Norwegian University of Science and Technology, Trondheim, Norway

> Pearcy WG, Lorz H, Peterson W (1979) Comparison of the feeding habits of migratory and non-migratory Stenobrachius leucopsarus (Myctophidae). Mar Biol 51:1-8

> Pearre S (2003) Eat and run? The hunger/satiation hypothesis in vertical migration: history, evidence and consequences. Biol Rev Camb Philos Soc 78:1-79

> Roe HSJ, Badcock J (1984) The diel migrations and distributions within a mesopelagic community in the north east Atlantic. 5. Vertical migrations and feeding of fish. Prog Oceanogr 13:389-424

Røstad A (2006) Fish behavior and implications for acoustic abundance estimates and ecological research. $\mathrm{PhD}$ thesis, University of Oslo, Norway

Soule M, Barange M, Solli H, Hampton I (1997) Performance of a new phase algorithm for discriminating between single and overlapping echoes in a split-beam echosounder. ICES J Mar Sci 54:934-998

Sutton TT, Hopkins TL (1996a) The species composition, abundance, and vertical distribution of the stomiid (Pisces: Stomiidae) fish assemblage of the Gulf of Mexico. Bull Mar Sci 59:530-542

Sutton TT, Hopkins TL (1996b) Trophic ecology of the stomiid (Pisces: Stomiidae) fish assemblage of the eastern Gulf of Mexico: strategies, selectivity and impact of a top mesopelagic predator group. Mar Biol 127:179-192

Thomson RE, Allen SE (2000) Time series acoustic observations of macrozooplankton diel migration and associated pelagic fish abundance. Can J Fish Aquat Sci 57:1919-1931

Torres JJ, Childress JJ (1983) Relationship of oxygen consumption to swimming speed in Euphausia pacifica. 1. Effects of temperature and pressure. Mar Biol 74:79-86

- Trevorrow MV (2005) The use of moored inverted echo sounders for monitoring meso-zooplankton and fish near the ocean surface. Can J Fish Aquat Sci 62:1004-1018

Warrant EJ, Locket NA (2004) Vision in the deep sea. Biol Rev Camb Philos Soc 79:671-712

Williamson CE (1993) Linking predation risk models with behavioral mechanisms: identifying population bottlenecks. Ecology 74:320-331

> Wolf M, Van Doorn GS, Leimar A, Weissing FJ (2007) Life history trade-offs favour the evolution of animal personalities. Nature 447:581-584

- Wright DI, O'Brien WJ (1984) The development and field test of a tactical model of the planktivorous feeding of white crappie (Pomoxis annularis). Ecol Monogr 54:65-98

Xie Y (2000) A range-dependent echo-association algorithm and its application in split-beam sonar tracking of migratory salmon in the Fraser River watershed. IEEE J Oceanic Eng 25:387-398

- Zamon JE, Greene CH, Meir E, Demer DA, Hewitt RP, Sexton $S$ (1996) Acoustic characterization of the 3-dimensional prey field of foraging chinstrap penguins. Mar Ecol Prog Ser 131:1-10 